\title{
Warum sagen wir etwas und tun genau das Gegenteil?
}

\section{Jean Martin}

Dr. med., Mitglied der Redaktion und ehemaliges Mitglied der Nationalen Ethikkomission

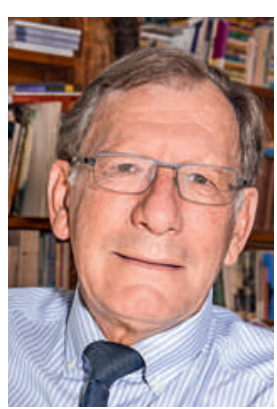

Literatur

1. George Marshall, englischer Forscher, in Don't even think about it Why our brains are wired to ignore climate change (Bloomsbury, London, 2014); einige Kapitel sind übersetzt erschienen in La Revue Durable, Nr. 56 , Januar-März 2016, S. 16-61.

2.https://www.google.ch/ search?q=great+acleration \&newwindow

jean.martin[at]saez.ch
Immer mehr Leute realisieren, dass die Nutzung von nicht erneuerbaren Ressourcen und ihre Folgen auf das Klima entscheidende Einflüsse darstellen. Das Pariser Abkommen vom Dezember 2015 war ein wichtiger Schritt in die richtige Richtung und im April dieses Jahres bestätigten 175 Staaten ihr Engagement in New York. Dennoch machen die Regierungen ebendieser Staaten (ausser gerade mal Bhutan!) keine Anstalten, in ihrem Bestreben nach einer Verbesserung der Lebensumstände ihrer Bürger ernsthaft in Richtung eines echten Paradigmenwandels zu handeln. Sie sehen ihr Heil weiterhin nur in einem starken Wachstum «im alten Stil». Susana Jourdan und Jacques Mirenowicz sind die Gründer der exzellenten Zeitschrift La Revue Durable. Kürzlich sprach Jacques Mirenowicz anlässlich einer Vortragsreihe der Universität Lausanne zum Thema «Welche Alternativen für unsere Welt?». Die Klima-Diplomatie, sagt er, verzeichnete in Paris einen schönen Erfolg. Aber obwohl sie Teil der Regierungstätigkeit der Länder ist, fristet sie überall nur Mauerblümchendasein, dahin abgedrängt von den politischen "Supertankern», d.h. anderen Ministerien (Wirtschaft, Finanzen). Einige sprechen von Schizophrenie. Jedenfalls geht es um eine schwerwiegende Inkohärenz der staatlichen Massnahmen: Wir sagen etwas und tun genau das Gegenteil. Mirenowicz erinnert an eine berühmte Begebenheit um Bundesrichter Frankfurter vom Obersten Gerichtshof der USA, der 1943 dem polnischen Diplomaten Jan Karski, der in den Westen geeilt war, um über die Vernichtung der Juden durch die Nazis zu berichten, zur Antwort gab: "Ich muss ganz ehrlich sagen, ich bin nicht imstande, Ihnen dies zu glauben»; auf eine spätere Kritik entgegnete er: «Ich sagte damals nicht, dass der junge Mann lüge, sondern dass ich ihm nicht glauben könne.» Mutatis mutandis sind wir heute genauso: Tagtäglich gibt es Hinweise, dass es ein riesiges Problem gibt, aber wir wandeln unser Wissen nicht in Taten um [1]. Natürlich ist es erst an der Politik, Entscheidungen $\mathrm{zu}$ treffen, aber jede und jeder kann sich engagieren.

In diesem Sinne gründete La Revue Durable «Artisans de la transition», einen Verein, der sich zum Ziel gesetzt hat, "die Orte zu mehren, an denen es möglich ist, gemeinsam den Wandel zu leben", hin zu einer Gesell- schaft, deren ökologischer Fussabdruck (viel) kleiner sein wird. Durch Einzelaktionen oder gemeinsame/genossenschaftliche Aktionen, zum Beispiel in der Lebensmittelproduktion (Lokalesser werden - Leute, die Lokales essen) und der Unabhängigkeit von fossiler Energie. Wie kann es möglich sein, nicht zu bemerken, wie durch rasche Mutation(en) sich alles immer mehr zum Schlechten wendet? Wie würde Donald Trump reagieren, falls er Präsident der Vereinigten Staaten wird, wenn man ihn auffordert, die sinnlose Verschwendung und das Wachstum zu bremsen? Donald Trump wird nicht verhandeln, er wird keine Lösungen suchen, wo jeder seinen Beitrag (in Abhängigkeit seiner Verantwortung) leisten müsste. Er wird Krieg führen, auf die eine oder andere Weise - wirtschaftlich, digital, militärisch.

In seinem Vortrag bezog sich Mirenowicz auf die 24 Grafiken, bekannt unter dem Titel Great Acceleration [2]: exponentielles Wachstum in Bezug auf Weltbevölkerung, Wasser- und Energieverbrauch, Treibhausgase, Versauerung der Weltmeere, Abbau der Biosphäre, Abholzung der Regenwälder, Anzahl hergestellter Autos usw. Dies sind die harten Daten, die die unkontrollierte Zunahme der Produktion und des Konsums aufzeigen und darum spricht man ja von der anthropogenen Ära. Diese harten Daten verbieten es geradezu, das Problem an sich zu leugnen und zu sagen everything is going to be allright - wie dies noch gewisse Schöngeister tun, die es «besser wissen».

Wenn dies auch sehr beunruhigend ist, scheint mir doch eine acceleration feststellbar, die Anlass zur Hoffnung gibt, nämlich die Sensibilisierung der millennials (Jahrgänge 1985 bis 2000): Der Vortrag von Mirenowicz fand am Mittwochabend vor Auffahrt statt, bei strahlendem Wetter ... und dennoch kamen gut hundert Studierende (und einige Ehemalige). Wohl ein Zeichen dafür, dass nicht nur ein paar wenige Rufer in der Wüste über eine lebenswerte Zukunft nachdenken möchten. Dies ist auch die Botschaft des vielbeachteten Films Demain. Die junge Generation erkennt, dass die "heisse Kartoffel», die wir ihnen weiterreichen, ohne Paradigmenwandel zu Schwierigkeiten und Dramen führen wird, deren Grösse und Auswirkungen wir heute nur schwer erahnen können. 